\title{
Correction of isolated secundum atrial septal defect in infancy
}

\author{
C BULL, J DEANFIELD, M DE LEVAL, J STARK, J F N TAYLOR, AND F J MACARTNEY \\ Thoracic Unit, The Hospital for Sick Children, London
}

SUMMARY Although it is a common congenital cardiac lesion, secundum atrial septal defect (ASD) rarely presents in infancy. Its natural history in the first two decades of life is generally benign. Reports of symptomatic ASD in early childhood ${ }^{1-3}$ stress the place of conservative management, and recommend that the operation should be deferred until school age. ${ }^{4}$ Few accounts of the indications for surgery in infancy exist. We present our experience of 6 patients who failed to respond adequately to conservative treatment and required operation for intractable heart failure due to isolated secundum ASD in the first year of life. As their presentation and physical signs were not typical of ASD seen in later childhood, they presented problems both of diagnosis and management.

\section{Methods}

Between 1965 and 1979 cardiac catheterisation was undertaken in 7 symptomatic infants in whom the diagnosis proved to be isolated secundum atrial septal defect (ASD). Six of them required closure of the defect in the first year of life. Records of these 6 patients were analysed for details of history, physical signs, electrocardiogram (ECG), chest $x$-ray film, cardiac catheterisation data, and operative findings. Survivors have been followed up for between 1 and 12 years.

Any patient with an ostium primum defect, mitral valve lesion, or other left-to-right shunt at the time of bypass surgery is excluded from the study.

\section{Results}

Details of the 5 girls and 1 boy are shown in Table 1 .

The age at initial presentation ranged from 6 days to 6 months. When first seen 3 patients were in severe congestive failure, 4 had evidence of failure to thrive, and 1 presented with a respiratory infection. By the time of surgery, all were in uncontrolled cardiac failure despite treatment with digoxin and diuretics, and all were below the 3rd centile for height and weight. Although such features constituted the indications for surgery in 5 of the 6 patients, operation was undertaken as an emergency for 1 patient who required preoperative mechanical ventilation. Although presenting at age 6 months, a seventh infant did not come to surgery until one year later and is therefore excluded from the study.

The physical signs and the investigations performed before cardiac catheterisation are shown in Table 2. All patients had some evidence of cardiac failure and one was cyanosed. All had ejection systolic murmurs at the left sternal edge and 4 had mid-diastolic murmurs, although these were not always interpreted as tricuspid flow murmurs. The first heart sound was normal in all 6 patients, with a widely split second heart sound in two.

Table 1 Details of the infants with isolated secundum atrial septal defect

\begin{tabular}{|c|c|c|c|c|c|}
\hline Case & $\begin{array}{l}\text { Age at } \\
\text { presentation }\end{array}$ & $\begin{array}{l}\text { Congestive cardiac } \\
\text { failure }\end{array}$ & Failure to thrive & $\begin{array}{l}\text { Respiratory tract } \\
\text { infection }\end{array}$ & Other \\
\hline 1 & 6 months & At presentation & At presentation & At surgery & \\
\hline 2 & 1 month & At surgery & At presentation & At presentation & \\
\hline 3 & 6 weeks & At presentation & At surgery & - & \\
\hline 4 & 1 month & At surgery & At presentation & At surgery & $\begin{array}{l}\text { Duct ligated at } 6 \text { months, } \\
\text { no improvement }\end{array}$ \\
\hline 5 & 6 days & At presentation & At surgery & 一 & $\begin{array}{l}\text { Duct ligated at } 1 \text { month, } \\
\text { no improvement }\end{array}$ \\
\hline 6 & 6 days & At surgery & At surgery & At surgery & $\begin{array}{l}\text { Intramyocardial injection at } \\
\text { first catheter. Tiny VSD }\end{array}$ \\
\hline
\end{tabular}


Table 2 Physical signs and investigation

\begin{tabular}{|c|c|c|c|c|c|c|c|}
\hline Case & Cardiac failure & Cyanosis & Murmur & Second heart sound & $E C G$ & $\begin{array}{l}\text { Precatheter } \\
\text { diagnosis }\end{array}$ & $\begin{array}{l}\text { Postcatheter } \\
\text { diagnosis }\end{array}$ \\
\hline 1 & + & 0 & Esm, mdm & Normal & $1^{\circ}$ block RAH RVH & A-V canal & ASD \\
\hline 2 & + & 0 & Esm & Widely split & RVH rsR 1 & PDA & ASD \\
\hline 3 & + & + & Esm & Loud $\mathbf{P}_{2}$ & RVH & TAPVD & ASD \\
\hline 4 & + & 0 & Esm, mdm & Loud $\mathrm{P}_{2}^{2}$ & RAH RVH & VSD & ASD, PDA \\
\hline 5 & + & 0 & Esm, mdm & Loud $\mathbf{P}_{2}$ & Biventricular hypertrophy & Truncus arteriosus & ASD, PDA \\
\hline 6 & + & 0 & Esm & Widely split loud $\mathbf{P}_{\mathbf{2}}$ & RVH & VSD & ASD \\
\hline
\end{tabular}

Esm $=$ ejection systolic murmur; $\mathrm{mdm}=$ mid-diastolic murmur; $1^{\circ}$ block $=$ first degree atrioventricular block; $\mathbf{R A H}=$ right atrial hypertrophy; $\mathbf{R V H}=$ right ventricular hypertrophy; $\mathrm{A}-\mathrm{V}=$ atrioventricular; $\mathbf{A S D}=$ atrial septal defect; PDA = persistent ductus arteriosus; TAPVD = total anomalous venous drainage.

Standard scalar ECGs showed sinus rhythm and right ventricular hypertrophy in all patients. Only one had an rsR prime pattern over the right ventricular leads and one had first degree atrioventricular block. The chest $x$-ray films showed cardiomegaly and pulmonary vascular plethora in all patients.

The ausculatory findings were not generally typical of ASD seen later in childhood, and the diagnosis of ASD was not made on clinical grounds before cardiac catheterisation in any patient. The true diagnosis was confused with other causes of left-to-right shunt in 4 patients (ventricular septal defect, persistent ductus arteriosus, or atrioventricular canal) and with other causes of cyanosis (total anomalous pulmonary venous drainage) or of cardiac failure (truncus arteriosus). At initial cardiac catheterisation 2 patients were shown to have a persistent ductus arteriosus in addition to the ASD. Both patients underwent ligation of the ductus, but the condition of neither improved. Each was recatheterised before bypass surgery.

The cardiac catheterisation findings before surgery are summarised in Table 3. There was a left-to-right shunt at atrial level with a pulmonary to systemic flow ratio of greater than 2:1 in all patients and above 3:1 in three. No other left-to-right shunts were detected. Mean left and right atrial pressures were equal in 5 and pulmonary artery pressure was greater than half systemic pressure in 4 of the 6 patients. Left ventricular injections were performed on all patients but no angiographic evidence of a mitral valve lesion or of left ventricular dysfunction was found. One child had evidence of a tiny ventricular septal defect when first catheterised, but no shunt was detected on oxymetry.

\section{Operative findings}

Surgical closure of a secundum ASD using cardiopulmonary bypass was performed in the 6 patients between ages 3 and 9 months (Table 4). Four operations were performed under moderate hypothermia. In 5 cases a large defect of secundum type (diameters ranging from 1.5 to $3.2 \mathrm{~cm}$ ) was closed, 2 using a patch and 3 by direct suture. In one case a secundum defect was associated with anomalous drainage of the right upper and lower pulmonary veins directly to the right atrium. The pulmonary veins were redirected to the left atrium

Table 4 Operative findings

\begin{tabular}{llll}
\hline Case & $\begin{array}{l}\text { Ageat operation } \\
\text { (months) }\end{array}$ & $\begin{array}{l}\text { Additional } \\
\text { findings }\end{array}$ & Outcome \\
\hline 1 & 8 & & Well \\
2 & 9 & & Well \\
3 & 3 & PAPVD & Died \\
4 & 9 & & Well \\
5 & 6 & & Well \\
6 & 5 & & Died \\
\hline
\end{tabular}

PAPVD $==$ partial anomalous pulmonary venous drainage.

Table 3 Catheterisation data

\begin{tabular}{|c|c|c|c|c|c|c|c|c|c|c|c|}
\hline Case & $\begin{array}{l}\text { Age at last } \\
\text { catheter } \\
\text { (months) }\end{array}$ & $\begin{array}{l}R A \\
(m e a n) \\
(m m H g)\end{array}$ & $\begin{array}{l}L A \\
(\text { mean }) \\
(m m H g)\end{array}$ & $\begin{array}{l}R V \\
(m m H g)\end{array}$ & $\begin{array}{l}P A \\
(m m H g)\end{array}$ & $\begin{array}{l}L V \\
(m m H g)\end{array}$ & $\begin{array}{l}Q p \\
(l / \min )\end{array}$ & $Q s$ & $Q p / Q s$ & $\begin{array}{l}R p \\
\left.\text { (units } m^{2}\right)\end{array}$ & $R s$ \\
\hline $\begin{array}{l}1 \\
2 \\
3 \\
4 \\
5 \\
6\end{array}$ & $\begin{array}{l}8 \\
9 \\
3 \\
9 \\
1 \\
5\end{array}$ & $\begin{array}{l}7 \\
8 \\
4 \\
5 \\
7 \\
4\end{array}$ & $\begin{array}{r}10 \\
8 \\
4 \\
5 \\
7 \\
4\end{array}$ & $\begin{array}{l}78 / 4 \\
40 / 0 \\
65 / 0 \\
75 / 8 \\
52 / 6 \\
80 / 0\end{array}$ & $\begin{array}{l}80 / 38 \\
37 / 18 \\
70 / 30 \\
70 / 15 \\
44 / 10 \\
70 / 20\end{array}$ & $\begin{array}{c}95 / 3 \\
105 / 10 \\
95 / 0 \\
105 / 8 \\
80 / 0 \\
90 / 0\end{array}$ & $\begin{array}{c}6 \cdot 6 \\
17 \\
9 \\
17 \\
8 \cdot 5\end{array}$ & $\begin{array}{l}3 \cdot 1 \\
5 \cdot 8 \\
4 \cdot 5 \\
4 \cdot 6 \\
2 \cdot 5\end{array}$ & $\begin{array}{r}2: 1 \\
3: 1 \\
2: 1 \\
>3: 1 \\
3: 1 \\
2: 1 \\
\end{array}$ & $\begin{array}{l}6 \\
1 \\
4 \\
2 \cdot 3 \\
0 \cdot 6 \\
\text { unt calculatic } \\
\text { e to pulmona } \\
\text { aturation) }\end{array}$ & $\begin{array}{l}21 \\
8 \\
13 \\
12 \\
22 \\
\text { unreliable } \\
\text { y venous }\end{array}$ \\
\hline
\end{tabular}

$\mathbf{R A}=$ right atrium; $\mathbf{L A}=$ left atrium; $\mathbf{R V}=$ right ventricle; $\mathbf{P A}=$ pulmonary artery; $\mathbf{L V}=$ left ventricle; $\mathbf{Q p}=$ pulmonary blood flow $\mathrm{Qs}=$ systemic blood flow $\mathbf{R p}=$ pulmonary vascular resistance; $\mathbf{R s}=$ systemic vascular resistance. 


\section{Postoperative course}

One patient (Case 3), the earliest in the series, died at operation. This child had required mechanical ventilation preoperatively and the procedure had been undertaken as an emergency. Another patient (Case 6) required inotropic support for the discontinuation of bypass; she remained hypoxic and hypotensive and died 24 hours postoperatively in a low cardiac output state. Necropsy showed gross and histological changes of pulmonary vascular disease. One patient (Case 1) had a difficult early postoperative course with two cardiac arrests in the first 48 hours and her recovery was protracted. Now, 12 years later, she still has ECG evidence of right ventricular hypertrophy. The remaining 3 patients had uneventful postoperative courses. The 4 surviving patients have been followed up for between 1 and 12 years and all remain asymptomatic on no cardiac medication. Although each is below the 10th centile for weight, none has been recatheterised postoperatively.

\section{Discussion}

ASD is often detected incidentally in asymptomatic children. The typical ausculatory complex of a pulmonary ejection murmur, tricuspid diastolic flow murmur, and fixed split second heart sound is accompanied by ECG changes of right ventricular hypertrophy and an rsR prime pattern in the right ventricular leads. There is cardiac enlargement, prominence of the pulmonary artery, and pulmonary plethora. So characteristic is this clinical picture that it is often possible to refer a patient with a large defect for surgery without prior cardiac catheterisation. Operation is electively carried out in the year before the child starts school because of the risk of developing pulmonary vascular disease, atrial arrhythmias, heart failure, and death in middle age.

The children under 1 year of age presented here differ from the 'typical' group in many respects. All were severely symptomatic, all were in uncontrolled congestive cardiac failure, all had failure to thrive at the time of surgery. None had the typical ausculatory complex which might have aided diagnosis before catheterisation and only one had an rsR prime pattern on the ECG. Four patients had pulmonary artery pressures at greater than two-thirds of systemic levels, a degree of pulmonary hypertension rarely found in the asymptomatic older child. It is indeed possible that in these symptomatic infants the pulmonary vascular obstructive disease is the primary abnormality, the ASD being an incidental, although exacerbating finding. Hunt and Lucas $^{3}$ followed up 11 patients presenting with ASD and congestive heart failure in infancy. They noted that the physical findings, while generally 'atypical' on presentation became 'typical' at about 2 years of age. Two patients, initially without an rsR prime pattern, developed this feature by age 2 years.

Small published series of ASD presenting in infancy encourage the conservative management of these patients. ${ }^{134}$ Phillips et al. ${ }^{2}$ maintain that most infants can be managed medically, to be treated surgically later in the conventional way. The condition of our patients deteriorated on medical treatment so that operation became necessary. Two patients died postoperatively, one with grade IV pulmonary vascular disease (Heath and Edwards classification $)^{5}$ at age 5 months. A third had a difficult postoperative course and has evidence of residual right ventricular hypertrophy. Significant mortality was also noted by Hunt and Lucas ${ }^{3}$ in their series and both patients operated in the first year of life died, but Phillips et al. ${ }^{2}$ reported 3 operations with no mortality in this age group.

ASD should be considered in the differential diagnosis of infants presenting in cardiac failure, with failure to thrive, or with cyanosis, which may be related to pulmonary infection and pulmonary venous desaturation. The diagnosis is confirmed at cardiac catheterisation and the child is initially managed with medical treatment. However, if the condition of the patient fails to improve, surgical correction should be undertaken without undue delay as symptomatic ASD can be associated with severe pulmonary vascular obstructive disease in this age group.

C B was supported by a Research Training Fellowship awarded by Action Research for the Crippled Child, and F J M was supported by the Vandervell and British Heart Foundations.

\section{References}

1 Spangler J G, Feldt R H, Danielson G K. Secundum atrial septal defect encountered in infancy. $J$ Thorac Cardiovasc Surg 1976; 71: 398-401.

2 Phillips S J, Okies J E, Henken D, Sunderland C O, Starr A. Complex of secundum atrial septal defect and congestive heart failure in infants. $J$ Thorac Cardiovasc Surg 1975; 70: 696-700.

3 Hunt C E, Lucas R V, Jr. Symptomatic atrial septal defect in infancy. Circulation 1973; 47: 1042-8.

4 Dimich I, Steinfeld L, Park S C. Symptomatic atrial septal defect in infants. Am Heart J 1973; 85: 601-4.

5 Heath D, Edwards J E. The pathology of hypertensive pulmonary vascular disease. A description of six grades of structural changes in the pulmonary arteries with special reference to congenital cardiac septal defects. Circulation $1958 ; 18$ : 533-47.

Correspondence to Professor F J Macartney, The Hospital for Sick Children, Great Ormond Street, London WC1N 3JH.

Received 23 September 1980 